\title{
Evolución e importancia del pensamiento histórico de fray Servando Teresa de Mier
}

\author{
Eduardo San José Vázquez \\ Universidad de Oviedo
}

Resumen:

El presente estudio intenta mostrar la relevancia del pensamiento histórico de fray Servando Teresa de Mier en el contexto de los procesos constituyentes de las repúblicas hispanoamericanas. Las conclusiones que aquí se ofrecen se apartan de la visión pintoresca del padre Mier, la que arrojan los estudios y biografías atenidos a los avatares vitales del dominico o que consideran su Sermón de Guadalupe como puntal de su extensa obra. Por el contrario, este trabajo trata de aclarar la importancia de su Historia de la revolución de Nueva España y de su opinión contraria al federalismo en los debates constitucionalistas del momento.

\section{Palabras clave:}

Fray Servando Teresa de Mier. Independencia americana. Pensamiento consTITUCIONAL.

La azarosa vida del dominico novohispano fray Servando Teresa de Mier ha oscurecido los aspectos más severos de su ideología y de su legado hispanoamericano. A esto se ha unido la desproporcionada importancia concedida a aquella primera obra (Sermón de Guadalupe, 1794) que determinó su persecución CES.XVIII, núm. 15 (2005), págs. 209-232. 
política e inquisitorial y, en gran medida, su biografía, pero que no alcanza a desvelar la auténtica trascendencia histórica del personaje. Para David A. Brading $^{1}$, la fascinación picaresca por la vida del dominico mexicano ha desviado la atención sobre la originalidad de su obra y sobre las cualidades más graves de su pensamiento histórico, político y teológico. Edmundo O’Gorman atribuye al perfil novelesco de su existencia la relativa despreocupación de los historiadores por los frutos, sensiblemente más reposados, de su pensamiento constitucionalista. Éste se manifiesta en un momento crítico de la historia hispanoamericana, como fueron los dos congresos constituyentes mexicanos de 1822 y 1823, de los que fue testigo y actor el controvertido dominico. Para O'Gorman, este desconocimiento postrero y la connotación eminentemente pintoresca del fraile podrían explicarse por la derrota de la opción política defendida por fray Servando ${ }^{2}$. En cualquier caso, el atractivo perfil biográfico del fraile continúa subordinando el resto de sus facetas personales, volviendo casi insalvable el prejuicio que da por seguros la imprevisión, el resentimiento antiespañol y el independentismo utopista del autor del delirante sermón de 1794 y protagonista, más tarde, de incontables e indecibles fugas.

El pintoresquismo es una de las justificaciones determinantes de la mayoría de los recuentos biográficos del fraile. Sus biógrafos tradicionales llevan a cabo relatos asimilables en último extremo a la recreación puramente novelesca. Con matices, sucede así en los volúmenes de José Eleuterio González ${ }^{3}$, Eduardo de Ontañón ${ }^{4}$ o Artemio de Valle-Arizpe. Así, el último de estos biógrafos llega a calificar a su personaje como «el alucinado padre Mier ${ }^{5}$. Esta pulsión expresionista se adueña, asimismo, de una parte considerable de la historiografía ocupada del padre Mier. El polígrafo mexicano Alfonso Reyes anota esto mismo cuando le dedica una de las semblanzas de sus Retratos reales e imaginarios. Ya percibe entonces que «fray Servando perdura sobre todo en el recuerdo de sus compatriotas por esa ráfaga de fantasía que anima toda su existencia ${ }^{6}{ }$. El mismo Reyes concluye que «el P[adre] Mier hubiera sido un extravagante, a no

1 Vid. David A. Brading, Los orígenes del nacionalismo mexicano, México, Secretariado de Educación Pública, 1973, págs. 62-63.

2 Vid. Edmundo O’Gorman, «Prólogo» a fray Servando Teresa De Mier, Ideario político, Caracas, Biblioteca Ayacucho, 1978, pág. IX.

3 Vid. José Eleuterio González, Biografía del benemérito mexicano D. Servando Teresa de Mier y Noriega y Guerra, Monterrey, Imprenta de Jose Sáenz, 1876.

4 Vid. Eduardo de Ontañón, Desasosiegos de fray Servando, México, Xochitl, 1948 [1. a ed., México, 1941].

5 Vid. Artemio de V alle-Arizpe, Fray Servando, Buenos Aires, Espasa-Calpe, 1951 [1. a ed., México, 1949], pág. 157.

6 Alfonso Reyes, «Fray Servando Teresa de Mier», en Retratos reales e imaginarios, Barcelona, Bruguera, 1984 [1. a ed., México, 1920], págs. 59-60. 
haberlo engrandecido los sufrimientos y la fe en los destinos de su nación ${ }^{7}{ }$. Reyes renovará este retrato en su prólogo a las Memorias de Mier, donde afirma que «la vida de fray Servando aparece bajo una luz fantástica ${ }^{8} »$, así como que, de haberse visto privado de sus sufrimientos vitales, su «vivacidad excesiva» lo habría convertido en un mero «estrafalario ${ }^{9}$ ». Atendiendo a su fecha de nacimiento, Germán Arciniegas califica al fraile como «la flor más rara que dio el mes de octubre ${ }^{10}{ }_{\text {}}$ (se entiende que en la primavera meridional). Edmundo O'Gorman coincide en señalar la importancia de estos rasgos de su carácter, si bien no deja de calificarlo como «una de las mentes más lúcidas y mejor enteradas — pese a extravagancias de carácter- de cuantos tomaron parte en los debates cuyo primordial objeto era constituir políticamente a la nación mexicana ${ }^{11}$ ».

Otros muchos autores no dejan de reconocer, en efecto, la importancia ideológica del padre Mier, más allá del interés novelesco de su biografía. No obstante, lo hacen preferentemente a través de su célebre sermón guadalupano, considerándolo como un gran dislate teológico calculado, sin embargo, sobre intenciones políticas ulteriores. Dicha obra se revalúa, entonces, como parte de una «epistemología patriótica» que pugnaba por el control de las fuentes historiográficas, tal como expresa Jorge Cañizares-Esguerra ${ }^{12}$. En esta línea, José Lezama Lima considera a fray Servando pieza destacada del nacimiento de una expresión americana, en la cual la disputa por la interpretación de las fuentes teologales se convertía en un modo de comenzar a sentirse y vindicarse americano ${ }^{13}$. Brading y Jacques Lafaye ${ }^{14}$ consideran que la importancia del sermón de 1794 entronca con la vieja disputa teológico-política por el derecho de los criollos a interpretar las fuentes americanas y con los albores de la fundación de una rama mexicana de la Iglesia Católica.

En comparación, puede observarse que el intento de valorar la figura histórica del padre Mier a partir de sus aportaciones ideológicas a los debates sobre la emancipación o al constitucionalismo mexicano no es tan claro ni mayoritario.

7 Idem.

8 A. Reyes, «Prólogo» a Fray Servando Teresa DE Mier, Memorias de fray Servando Teresa de Mier, Madrid, Editorial América, s.f., pág. XI.

$9 \quad$ Ibid., pág. XXI.

10 Germán Arciniegas, «Fray Servando», en América mágica. Los hombres y los meses, Buenos Aires, Sudamericana, 1961 [1. ed., Buenos Aires, 1959], pág. 257.

11 O’Gorman, «Presentación» de MiER, «El padre Mier en el Congreso Constituyente mexicano», loc. cit., pág. 237.

12 Vid. Jorge CañIZares-Esguerra, How to write the history of the New World: histories, epistemologies, and identities in the eighteenth-century Atlantic world, Standford, Standford University Press, 2001.

13 Vid. José Lezama Lima, La expresión americana, Madrid, Alianza, 1969 [1. a ed., La Habana, 1957], págs. 89-97.

14 Vid. Jacques LafaYe, Quetzalcóatl y Guadalupe. La formación de la conciencia nacional en México (prefacio de Octavio Paz), México, Fondo de Cultura Económica, 1977. 
No han faltado, con todo, quienes aprecien dicho valor. Éste ha sido el intento, entre otros autores, de O'Gorman y de Brading, así como el de los editores críticos de la Historia de la revolución de Nueva España ${ }^{15}$ escrita por Mier, o el de Luis Villoro, en su estudio del contexto constitucionalista mexicano ${ }^{16}$. Es oportuno señalar la importancia del pensamiento político de Mier, por encima de los rasgos accidentales de su biografía, que, tanto en la pluma del fraile como entre los historiadores, tiende a menudo a lo novelesco. Con esta misma intención, debe ponerse en suspenso la finalidad real del sermón guadalupano de Mier, que, independientemente del significado que más tarde hayan querido darle el fraile y algunos historiadores, parece más bien obra de la improvisación y del deseo de lucimiento que de un programa político. Una vez que tanto la vida como el sermón guadalupano pierden el excesivo protagonismo que tienen en el retrato más habitual de Mier, puede distinguirse mejor la importancia que tuvieron sus propuestas políticas en hombres como Simón Bolívar, Lucas Alamán, Carlos María Bustamante o, en general, en el proceso constituyente mexicano.

Curiosamente, no debe dejar de mencionarse en esta lista de valoraciones del pensamiento político de Mier una novela. Se trata de la conocida obra de Reinaldo Arenas El mundo alucinante (escrita en 1966 y publicada en 1969). Por causas evidentes, se ha tendido a identificar en esta obra una mera impostación autobiográfica del autor cubano. Un análisis más concienzudo permite observar, sin embargo, que los avatares de persecución y exilio que podían vincular a Arenas con el protagonista de su novela aún no habían tenido lugar. Esto invita a apreciar un aprovechamiento de la figura de Mier no sólo como emblema de una romántica disidencia, sino una verdadera valoración de su pensamiento histórico, como paradigma del posibilismo político, del antiutopismo y del antitotalitarismo que Arenas reclamaba al régimen nacido de la revolución cubana de 1959.

\section{Semblanza}

José Servando Teresa de Mier Noriega y Guerra nace en Monterrey el 18 de octubre de 1763. Descendiente por parte materna de una vieja familia criolla,

15 Vid. Mier, Historia de la revolución de Nueva España, antiguamente Anáhuac, o verdadero origen y causas con la relación de sus progresos hasta el presente año de 1813 (edición, introducción y notas de André Saint-Lu y Marie-Cécile Bénassy-Berling, coordinadores, prefacio de David A. Brading), Paris, Publications de La Sorbonne, 1990. Vid. también la edición facsimilar de la Historia de Mier, acompañada de un estudio crítico y anexos, a cargo de Manuel Calvillo (México, Instituto Mexicano del Seguro Social, 1980).

16 Vid. Luis Villoro, El proceso ideológico de la revolución de Independencia, México, Secretaría de Educación Pública, 1986 [1. ed., México, 1953]. 
considerada entre los primeros conquistadores de Nuevo León, por vía paterna era nieto de un escribano público, asturiano destinado en Monterrey, Joaquín de Mier y Noriega, e hijo de un funcionario metropolitano que llegó a ser gobernador interino de la provincia de Nuevo León. De estos dos orígenes señala el propio Mier su vínculo con varias casas españolas, como los duques de Granada y los marqueses de Altamira, mientras que, por la vía materna, aduce una ligazón, tan inverosímil como la anterior, con la sangre de la dinastía azteca, a través de Cuauhtémoc. Así lo subraya en varios de sus escritos, en una actitud que O’Gorman no deja de señalar como lo que, para él, es la pasión dominante del padre Mier: la egolatría. Por eso, nota que «pese a su acendrado republicanismo, fue siempre el padre Mier muy puntilloso en asunto tocante a su ascendencia aristocrática» ${ }^{17}$.

Los principales documentos que se pueden utilizar para reconstruir la vida de este fraile, ordenado dominico en 1779 y doctor en teología, son, en primer lugar, los propios escritos de Mier. Así su Apología (1818), en la que describe los antecedentes y pormenores dialécticos del Sermón de Guadalupe hasta la primera prisión en el castillo de San Juan de Ulúa (Veracruz), a la que se añadieron las relaciones del propio fraile hasta su huida desde Sevilla a Portugal en 1805. Ambos textos vienen siendo recogidos en un volumen como Memorias de fray Servando Teresa de Mier a partir de la edición de 1856 de Manuel Payno ${ }^{18}$. A dichas Memorias debe añadirse el Memorial apologético y una Exposición de la persecución que ha padecido desde el 14 de junio de 1817 hasta el presente de 1822, redactados en 1820 durante su última prisión, de nuevo en San Juan de Ulúa, junto a otros documentos con algún contenido más o menos biográfico ${ }^{19}$. Otras fuentes escritas con las que evocar la complicada existencia del padre Mier son varios de sus escritos de tipo político en los que ocasionalmente puede deslizar comentarios autobiográficos, como la Historia de la revolución de la Nueva España (1813); la Memoria político instructiva, texto de advertencia a los líderes patriotas mexicanos contra la solución autonomista ofrecida por el Plan de Iguala y redactado en 1821 desde su exilio en Filadelfia; el texto de la primera

17 O’Gorman, «Prólogo» a Mier, Ideario político, pág. x.

18 La Apología y una Relación de lo que sucedió en Europa al doctor D. Servando Teresa de Mier, después que fue trasladado allá por resultas de lo actuado contra él en México, desde julio de 1795 hasta octubre de 1805 fueron redactadas por Mier estando preso en la cárcel de la Inquisición de México en 1817. Fueron editadas por primera vez por Manuel Payno, en México, en 1856, como Vida, aventuras, escritos y viajes del Dr. Servando Teresa de Mier. Esta edición recoge juntos ambos textos. Las ediciones actuales suelen tomar la de José Eleuterio González, de 1876, siguiendo su título de Memorias de fray Servando Teresa de Mier.

19 El Memorial, la Exposición y demás textos de este periodo no fueron publicados hasta 1944. Vid. Mier, Escritos inéditos de fray Servando Teresa de Mier (Introducción, notas y ordenación de textos de J. M. Miquel y Vergés y Hugo Díaz-Thomé), México, El Colegio de México, 1944. 
intervención de fray Servando en el Congreso Constituyente mexicano, el 15 de julio de 1822, o su Profecía sobre la federación mexicana, como es conocido el texto de su famosa intervención en la sesión del 13 de diciembre de 1823. A estos textos se une la correspondencia personal del fraile, apenas conservada, pero que presenta a personajes como Juan Bautista Muñoz, Andrés Bello, el doctor Agustín Pomposo Fernández, amigo personal de Mier, o su principal opositor en los debates constitucionales, el padre Miguel Ramos Arizpe ${ }^{20}$. Aparte de los textos del fraile, los únicos testimonios verdaderamente directos de episodios de su vida son los que aparecen en los tomos III y IV de la Historia de Méjico (1852) de Lucas Alamán, donde relata la convivencia de ambos entre París y Londres ${ }^{21}$. Por último, las colecciones documentales en las que se recogen las dos causas levantadas contra el padre Mier, la inicial de 1795 y la posterior, «por infidencia y otros delitos», en 1817, son documentos notables para esta reconstrucción biográfica $^{22}$. De la suma de estas fuentes textuales suelen resultar las biografías clásicas que existen sobre el padre Mier.

El retrato histórico más extendido del padre Mier se debe a la celebridad suscitada a raíz de la persecución institucional que sufrió tras pronunciar su sermón guadalupano de 1794, así como a su infatigable resistencia a los castigos personales de varia índole. La fama de orador de Mier había provocado que fuera propuesto para hablar en las honras fúnebres de Hernán Cortés, el 8 de noviembre de 1794. El éxito de aquella ocasión hizo que el arzobispo Núñez de Haro le encargara un nuevo sermón. El 12 de diciembre del mismo año, en presencia del virrey y del arzobispo, Mier pronuncia en la Colegiata de Guadalupe de México su famoso sermón sobre la tradición de la virgen de Guadalupe, en el que niega la leyenda de la aparición de Tepeyac en 1531, según la cual la Virgen habría dejado su imagen sagrada en la capa (tilma) del indio Juan Diego. Mier se inspiró en las conclusiones del licenciado José Ignacio Borunda, quien sostenía que el culto de Guadalupe se transmitió en la capa del propio apóstol santo Tomás, que habría predicado en el Nuevo Mundo a la muerte de Cristo. Borunda sostenía que la imagen mítica de Quetzalcóatl y santo Tomás eran, en

20 Para una lista de las colecciones y estudios realizados acerca de la correspondencia de Mier, vid. Saint-Lu y Bénassy-Berling, «Introducción» a Mier, Historia, págs. CXVIII-CXIX.

${ }_{21}$ Vid. Lucas Alamán, Historia de México, Lara, México, 1849-1852. Tomo III, págs. 54-65; tomo IV, págs. 552-568, 593 y 705. Para una hipótesis acerca de las divergentes noticias biográficas asentadas por Alamán y por Mier, en sus Memorias, vid. V ALLE-ArizPe, loc. cit., págs. 93-101. Alfonso Reyes amplía este posible corpus textual a algunos historiadores que aportan testimonios de carácter fragmentario o indirecto, como José María Luis Mora, Carlos María Bustamante o W.D. Róbinson. Vid. REYEs, «Prólogo», págs. XX-XXI.

${ }^{22}$ Los testimonios de la causa levantada contra Mier por el Sermón y los de la abierta tras el fracaso de su expedición junto a Mina se recogen respectivamente en J.E. Hernández y Dávalos, Colección de documentos para la historia de la guerra de independencia de México de 1808 a 1821 (Vols. III y VI), México, El Sistema Postal, 1879-1882. 
realidad, la misma figura. En esta tesis, el culto mariano era devuelto, por su parte, a la advocación telúrica de la divinidad azteca Tonantzin. Esta hipótesis, que forma parte de una larga tradición criolla de cuestionamiento de la autoridad de la historiografía peninsular, surge de la versión que discute el protagonismo de los españoles como divulgadores del Evangelio en América, y les retira, con ello, cualquier crédito histórico y moral a los títulos de posesión de la metrópoli. Así lo había comenzado a exponer Guamán Poma de Ayala en su Nueva corónica (1600). Asimismo, había sido defendida por Fernando de Alva Ixtlilxochitl (1575-1648) y otros autores posteriores, como Carlos de Sigüenza y Góngora (1645-1700) y Mariano Fernández de Echeverría y Veytia (1718-1779) ${ }^{23}$. Parece que el propio Mier era consciente de tales antecedentes, como demuestra en su intervención en el primer congreso constituyente y, especialmente, en su Carta de despedida a los mexicanos ${ }^{24}$.

Unos días después de pronunciar el sermón, Mier es arrestado en su propia celda, y en 1795 comienza la interminable serie de juicios, destierros, prisiones y fugas que jalonan su vida. Tras la prisión en la fortaleza de San Juan de Ulúa, Mier es desterrado a España, donde sufre prisión en Cádiz y en el convento dominico de Las Caldas, cerca de Santander. Siempre de acuerdo con el texto de sus Memorias, Mier se fuga para tratar de alcanzar la aldea de «Buelna de Asturias [Llanes], donde está la casa solariega de mi familiaa ${ }^{25}$. Es capturado, sin embargo, a los pocos días, y sale con pena de reclusión para el convento dominico de San Pablo, en Burgos, hasta fines de 1796. Fugándose otra vez, acude a Madrid para pedir la intervención del Consejo de Indias, tras lo cual es encerrado en el convento de los franciscanos de Burgos. Se vuelve a fugar, esta vez con éxito, a Bayona, donde conoce a Simón Rodríguez, quien fuera el pre-

23 Vid. Cañizares-Esguerra, loc. cit., págs. 213-217, 221-225 y 305-321. Los textos guadalupanos de estos tres autores, así como el sermón de Mier y su carta de 1797 a Juan Bautista Muñoz explicando su versión de la leyenda se reproducen en Ernesto de la Torre Villar y Ramiro Navarro de Anda (comps.), Testimonios históricos guadalupanos, México, Fondo de Cultura Económica, 1982. El volumen recoge un gran número de alegatos guadalupanos de diversa índole, desde la «Relación primitiva» (1541-1545) hasta el siglo XIX. En el siglo XVIII recopila además los de Lorenzo Boturini, Juan José Eguiara y Eguren, Miguel Cabrera, Francisco Xavier Clavijero, José María Téllez Girón y Juan Bautista Muñoz.

24 En ambos textos, Mier se reafirma tiempo después en el contenido esencial del Sermón, recordando los antecedentes historiográficos mencionados, en los que se sostenían versiones semejantes. En la Carta, además, continúa los delirantes estudios etimológicos que relacionan a Santo Tomás con Quetzalcóatl, copiados de Borunda, y ensaya una etimología de México que relaciona esta voz con el Cristianismo. Vid. Mier, «Carta de despedida a los mexicanos», en Ideario político, págs. 7-13; «El padre Mier en el Congreso constituyente mexicano» (sesión de 15 de julio de 1822), ibid., págs. 237-244.

25 Mier, Memorias de fray Servando Teresa de Mier (prólogo de Alfonso Reyes), Madrid, Editorial América, s.f., pág. 188. Para un estudio de los vínculos asturianos del padre Mier, vid. José Ignacio GraCiA Noriega, «Vida de fray Servando Teresa de Mier Noriega», Boletín del Instituto de Estudios Asturianos, XLI, 121 (1987), págs. 299-310. 
ceptor personal de Bolívar. Junto a él abre una academia de español en París, y por un tiempo llega a encomendársele una parroquia, la parisina de Santo Tomás de Aquino. En 1802 viaja a Roma para solicitar su secularización del papa, lo que finalmente se le concede en 1803, con reserva del ejercicio sacerdotal. Vuelto a Madrid con el fin de emprender desde España el regreso a América, lo capturan de nuevo y es encerrado durante un año. En 1804, se le envía preso al reclusorio de Los Toribios, en Sevilla. De aquí se fuga en dos ocasiones, hasta poder alcanzar con éxito Portugal, en $1805^{26}$. Según el testimonio de Mier en sus Memorias, en la travesía que lo saca de España por Ayamonte, alcanza a presenciar sobre el horizonte la batalla de Trafalgar. Fray Servando está lejos de adivinar que la suerte de la misma terminará decidiendo indirectamente el destino de las posesiones ultramarinas españolas, y que está contemplando, de hecho, el principio del fin del imperio hispánico.

A partir de este momento, las Memorias se interrumpen, siendo necesario el resto de los testimonios antes citados para completar la vida del ya entonces sacerdote secular. En Portugal sirve como secretario del cónsul general de España; pero con la invasión napoleónica de Portugal se une al general Gregorio Laguna, que formaba un ejército de resistencia a los franceses. En 1809, regresa a España, para participar en la guerra de independencia como cura castrense, agregado al Batallón de Voluntarios de Valencia. En Belchite, los franceses lo hacen prisionero mientras sirve en la división del general inglés Blake, pero consigue fugarse. En 1811, parte a Londres, donde permanecerá hasta 1816, con la única ausencia de una estancia parisina entre julio de 1814 y abril de 1815 . Hasta su salida de la capital inglesa, frecuenta a los liberales españoles y a los independentistas hispanoamericanos allí residentes y vinculados a alguna de las logias nacidas a raíz de la Logia Americana, fundada en 1797 por Francisco de Miranda.

Reviste especial trascendencia su contacto con el círculo intelectual de $E l$ Español, el periódico editado en la capital inglesa entre 1810 y 1814 por José María Blanco White, quien habría de ser uno de los grandes amigos de Mier. No obstante, ambos se enzarzan en una polémica a los pocos meses de la llegada de Mier. Contra las tesis de Blanco, que era favorable a una autonomía relativa de América y condenaba como prematura la declaración de Independencia venezolana realizada el 5 de julio de 1811, Mier costea a finales de ese año un opúsculo titulado Carta de un Americano al Español sobre su número XIX. Esto supone el inicio de una polémica con el redactor de El Español sobre la perti-

26 Para un estudio de la estancia sevillana de Mier hasta su salida definitiva hacia Portugal, vid. Carmen de Mora Valcárcel, «Fray Servando Teresa de Mier en los Toribios de Sevilla», en Andalucía y América en el siglo XIX, II, Sevilla, Escuela de Estudios Hispanoamericanos /CSIC, 1986, págs. 259-273. 
nencia de una demanda netamente independentista para la América española. En el periodo de un año, Mier y Blanco cruzarán sus opiniones en varios textos: Blanco, respondiendo desde las páginas de El Español, y Mier agregando una Segunda Carta en 1812 que, asimismo, aguardaba por la última réplica del sevillano ${ }^{27}$. En Londres concluye Mier, en 1813, su Historia de la revolución de Nueva España, que le había encargado dos años antes la esposa de José Iturrigaray, quien deseaba defender la fama del ex virrey de Nueva España. Ambos textos son índice suficiente de la actividad específicamente ideológica del padre Mier. Tales testimonios ayudan, además, a completar la importancia de su participación en la política americana.

En Londres conoce al liberal español Francisco Xavier Mina, militar exiliado y sobrino del general Espoz y Mina. Enterado Mier del levantamiento del cura Miguel Hidalgo en 1810 y de su posterior derrota, convence a Mina para organizar una conspiración independentista. Tras conseguir financiar en Inglaterra y Estados Unidos una pequeña expedición emancipadora, desembarcan en México en 1817, pero son descubiertos. Mina es ejecutado, y Mier queda preso de los realistas en Soto la Marina. Se lo traslada a las cárceles de la Inquisición en México (de nuevo, San Juan de Ulúa) y posteriormente es embarcado hacia España, en 1820. En la escala de La Habana, sin embargo, logra escaparse. Mier permanece en Estados Unidos hasta 1822, es decir, hasta un año después de que México haya conseguido su independencia. De vuelta en su país, es designado representante al Congreso Constituyente por Nuevo León. A pesar de esto, vuelve a ser encarcelado por sus discursos contra el nuevo imperio monárquico instaurado por Agustín de Iturbide. Cuando éste cae, Mier es repuesto como representante del restaurado Congreso Constituyente mexicano. Aun en estos últimos momentos de su vida, en los que el primer presidente republicano Guadalupe Victoria (como se hizo llamar el general Félix Fernández) le da alojamiento en el Palacio Nacional, Mier es un opositor de la política en el poder. En este caso, criticará hasta su muerte la opción del federalismo, a favor de un centralismo moderado y de la contención de las reformas en marcha, para las que juzgaba que México no estaba preparado. En su habitación del Palacio Nacional, muere fray Servando el 3 de diciembre de 1827, después de haber invitado personalmente a

27 Al contrario de lo que sucede con las réplicas de Blanco White desde El Español, los dos opúsculos de Mier que completan la polémica son particularmente difíciles de encontrar. O'Gorman reproduce solamente la Segunda Carta en su edición del Ideario político de Mier. Los dos textos londinenses de Mier se reproducen en Mier, Cartas de un americano, 1811-1812 (selección y notas de Manuel Calvillo), México, Secretaría de Educación Pública, 1987. La reproducción completa de los seis textos que en total integran la polémica y, especialmente, de las dos intervenciones de Mier, se encuentra depositada en la biblioteca del Instituto Universitario Feijoo de Estudios del Siglo XVIII. 
sus amigos, casa por casa, al acto de recibir la extremaunción. El mismo Miguel Ramos Arizpe le administró entonces el viático, en presencia del presidente, a petición de Mier.

\section{Ideario y religiosidad del padre Mier}

Alfonso Reyes divide la vida del padre Mier en tres grandes etapas ${ }^{28}$. La primera se vincula a su proceso de formación hasta 1794, cuando pronuncia el Sermón. La segunda está señalada por el inicio de su persecución y el exilio europeo, y la tercera etapa se abre con su regreso a México en 1817, junto a Mina. Según esto, podría establecerse una evolución ideológica que respondiera a las diferentes etapas vitales del fraile. Edmundo O'Gorman se acerca bastante a esta consideración, con la salvedad de que divide las dos últimas etapas de su ideario político poniendo el acento en las estancias en Londres, entre 1811 y 1816, y en Estados Unidos, entre 1820 y $1822^{29}$. Ambas marcarían la influencia determinante del democratismo whig inglés y del republicanismo norteamericano en el ideario político de Mier.

Con el fin de seguir la evolución del pensamiento histórico de Mier, se pueden emplazar uno o varios textos capitales en cada una de las tres etapas. La primera estaría representada por el Sermón. La segunda etapa, la de su experiencia londinense, cifraría su contenido ideológico en las dos cartas de la polémica con Blanco White y en su Historia. La tercera etapa, por su parte, se resumiría en las conclusiones políticas alcanzadas en Estados Unidos, con el matiz de adaptación posibilista a la realidad mexicana que Mier le da al republicanismo del norte. Estas ideas se expresan con claridad en las intervenciones de Mier ante el Congreso Constituyente. El documento más representativo es el famoso Discurso de las profecías, pronunciado en 1823.

Se puede adelantar la evolución ideológica del padre Mier a la luz de estos documentos escalonados en tres etapas: en la primera etapa, debe discutirse el contenido específicamente político y antiespañol del sermón guadalupano. Parece improbable que las intenciones secesionistas apreciadas en el texto se deban a algo más que a una interpretación posterior. Por su parte, la etapa inglesa marca el inicio del sentimiento antiespañol y decididamente independentista del fraile, lo que se puede verificar en las cartas de su polémica con Blanco White y en el inicio de una actividad propagandística que se destacará por una

28 Vid. ReyES, «Fray Servando Teresa de Mier», pág. 57.

29 Vid. O’Gorman, «Prólogo» a MIER, Ideario político, págs. XXII-XXIII. 
vindicación lascasiana y por el primer fruto historiográfico de la Independencia americana. La tercera etapa ayuda a apreciar el pensamiento constitucionalista que subyacía en los planes emancipadores de Mier. Las intervenciones de Mier en el Congreso Constituyente permiten descubrir el carácter moderado del proyecto de nación que se escondía debajo del independentismo belicista que había enarbolado el fraile.

\section{El «Sermón de Guadalupe»}

La principal incógnita historiográfica que ha despertado el Sermón de Guadalupe, que Mier pronuncia el 12 de diciembre de 1794, es el grado de intencionalidad política que podía haber motivado al joven fraile a cuestionar la leyenda tradicional de la virgen de Guadalupe. Las interpretaciones pueden dividirse en dos opiniones, no siempre discriminadas en diferentes autores, ya que un mismo historiador puede inclinarse en distinta medida por las dos. Por un lado, puede considerarse que el sermón guadalupano es uno de los textos precursores de la independencia hispanoamericana y que fue previsto como tal por su autor. Por el otro, es posible atenerse a las justificaciones que ofreció Mier durante su proceso de 1795, al afirmar que todo se había debido a la imprevisión y a un error en la fuente elegida, los papeles del licenciado Borunda. Se puede afirmar entonces que las intenciones políticas entrevistas por el arzobispo Núñez de Haro en el contenido del sermón y, más tarde, por la historiografía mexicana, se justifican a posteriori.

La primera opinión es apreciablemente la mayoritaria. No en vano, es la que ha conseguido prender la imagen de fray Servando en la historia americana. Así, Alfonso Reyes clasifica las tres etapas ideológicas del padre Mier a partir de esta primera época, que lo haría aparecer ya como «precursor de la Independencia ${ }^{30}{ }_{\text {». }}$ Germán Arciniegas califica el Sermón como «un grito religioso de independen$\operatorname{cia}^{31}{ }_{»}$. Con diferentes conclusiones, David Brading y Jacques Lafaye ${ }^{32}$ coinciden, sin embargo, en analizar el sermón guadalupano como uno de los gestos fundacionales de la identidad de México. Ésta se gestaría desde el momento en que se funda oficiosamente la Iglesia mexicana bajo el emblema licitador de la Virgen de Guadalupe. La sanción canónica del culto guadalupano, con su consagración solemne en 1737, supuso, para Brading, el inicio de la discriminación de una rama mexicana de la Iglesia Católica, y, a través de ella, la transformación de

\footnotetext{
30 ReYes, «Fray Servando Teresa de Mier», pág. 57.

31 Arciniegas, loc. cit., pág. 260.

32 Vid. Jacques LafaYe, Quetzalcóatl y Guadalupe. La formación de la conciencia nacional en México (prefacio de Octavio Paz), México, Fondo de Cultura Económica, 1977.
} 
aquél en un culto a la nación ${ }^{33}$. Octavio Paz ha matizado, no obstante, esta conclusión, refiriéndose en concreto a la obra de Lafaye, que prologa ${ }^{34}$. Paz sostiene que, para liquidar la instancia política de la Nueva España, los criollos forjadores de la idea de México debieron servirse del mito guadalupano, al tiempo que lo sustrajeron de manos de la curia peninsular para identificarlo con Tonantzin. Así se explica que los mestizos liberales que echaron los cimientos de la nueva nación-estado en el siglo XIX invocaran el pendón guadalupano al tiempo que trataban de destruir la cultura clerical de la Nueva España. Así, con la Reforma, la Iglesia fue expulsada de hecho de la política nacional. Por esto, para Paz, la Guadalupana no es más aglutinadora de la conciencia nacional que los mitos mesoamericanos.

De cualquier forma, con la trilogía «Guadalupe-Quetzalcóatl-Las Casas», opina Lafaye, la causa emancipadora se desembarazaba de lo que podía tener de inquietante para el orden de la propia sociedad criolla una «revolución» cuyo grito inicial había sido «¡Viva la religión!» ${ }^{35}$. El mismo Bolívar, desde su prudencia táctica, creyó que, en la práctica, otro proceso hubiera sido imposible o indeseable:

Felizmente, los directores de la independencia de México se han aprovechado del fanatismo con el mejor acierto, proclamando a la famosa virgen de Guadalupe por reina de los patriotas [...]. Con esto el entusiasmo político ha formado una mezcla con la religión, que ha producido un fervor vehemente por la sagrada causa de la libertad ${ }^{36}$.

Para reforzar la supuesta interpretación independentista del sermón guadalupano, puede ser útil verificar el profundo descreimiento que Mier llega a mostrar más adelante acerca de la existencia de la aparición misma. Mientras duró su primer proceso inquisitorial, Mier se defendía de haber atacado directamente la tradición guadalupana. Sostenía haberla situado en sus términos y naturaleza verdaderos, pero de ningún modo haber socavado la raíz de su existencia. Sin embargo, cuando redacta la Apología, en 1817, refuta en sí misma la tradición guadalupana e incluso el dogma mariano, ya que «la Concepción en gracia no es más que una opinión» ${ }^{37}$. Lo curioso es que, a pesar de que niega el propio

\footnotetext{
33 Vid. Brading, Mito y profecía en la historia de México, México, Vuelta, 1988, págs. 63-69.

34 Vid. Octavio PAZ, «Prefacio» a LafaYe, op. cit., págs. 11-25.

35 LafaYe, loc. cit., pág. 200.

36 Simón Bolívar, «Carta de Jamaica», en Doctrina del libertador (prólogo de Augusto Mijares, compilación, notas y bibliografía de Manuel Pérez Vila), Caracas, Biblioteca Ayacucho, 1976, págs. 73-74.

37 Mier, Memorias, pág. 418. Mier sigue, en cualquier caso, la doctrina de los dominicos, y se acoge para esta afirmación al breve del papa Gregorio XIII por el que podían defender la doctrina contraria en sus claustros.
} 
dogma, el fraile continuará defendiendo su versión prehispánica de la tradición, sin duda pensando en su utilitarismo político. Con esto, revela que, tal vez desde el principio de la polémica, Mier era consciente del valor del discurso metafísico para el control de los proyectos y de las identidades colectivas:

Saben los pícaros que así como con el pretexto de la religión se subyugó a la América, así la virgen de Guadalupe es el cabestro con que se llevan los mexicanos a beber agua a la fuente del burro ${ }^{38}$.

Desde esta manipulación descreída de la leyenda, Mier aparece como un mero historiador secular, dispuesto a contrarrestar la escatología falsaria de los españoles con sus mismas armas. Entonces sí, es muy probable que el joven fraile que dice el Sermón albergara una intención política patriótica, o, cuando menos, de vindicación criollista: «Los europeos, sin creer la tradición de Guadalupe, han gritado más alto que los criollos para destruir la especie de la predicación de Santo Tomás, porque creen que les quita la gloria de haber traído el Evangelio, y los iguala con los indios en cuanto a la imagen del Pilar». Pero, para ellos, «desgraciadamente, ha tocado la tecla un criollo brillante ${ }^{39}$. El fraile se insertaría así, como historiador o publicista, en las polémicas históricas por la «calumnia de América», como denomina Edmundo O'Gorman toda la corriente de opinión que, a lo largo del siglo XVIII y desde Europa, vertió una opinión peyorativa acerca de la naturaleza de América y de sus naturales ${ }^{40}$. Ésta es la precisa dimensión en que descubre O'Gorman los escritos políticos de Mier: antes que en la teología, en una lucha contra la dominación historiográfica española y contra el logocentrismo ilustrado europeo ${ }^{41}$. Asimismo, ésta es la verdadera impor-

$38 \quad$ Ibid., pág. 383.

39 Ibid., pág. 121.

40 Para una explicación de la «calumnia de América», vid. O’Gorman, Fundamentos de la historia de América, México, Imprenta Universitaria, 1942. Para comprender la polémica, es necesario referirse a algunas obras conocidas: Silvio Zavala, América en el espíritu francés del siglo XVIII, México, El Colegio Nacional, 1949; Antonello Gerbi, La disputa del Nuevo Mundo. Historia de una polémica. 1750-1900, México, Fondo de Cultura Económica, 1982 [1. ${ }^{a}$ ed., 1955]. La obra de Zavala atenúa, sin embargo, los testimonios principales del estudio de Gerbi, ya que presenta las numerosas excepciones entre los pensadores franceses del momento a la condena historiográfica del Nuevo Mundo. No obstante los autores que contempla Zavala casi nunca alcanzan el rango intelectual de los «calumniadores». Por su parte, en Ricardo García Cárcel, La leyenda negra. Historia y opinión, Madrid, Alianza, 1998, págs. 295-312, se encontrará un análisis de la polémica contemplada como un episodio consecuente de la «leyenda negra» contra lo hispánico.

41 Mier se instala con claridad en esta polémica con una de las notas publicadas como anexos a su Carta de un Americano al Español sobre su núm. XIX, de 1811. Es la conocida como «Quejas de los americanos». En ella, protesta por la marginación en las Cortes de Cádiz de los representantes americanos, a quienes se les impedía participar en pie de igualdad con los peninsulares. Mier aprovecha la ocasión para hacer una defensa americanista y para calificar como «bufonadas» las teorías acerca de la naturaleza y la cultura americanas 
tancia que otorga a la figura de fray Servando Jorge Cañizares-Esguerra, dentro de la confección de lo que este denomina como una «epistemología patriótica»: una lucha por el control de la historiografía a través de la relevancia y la autoridad concedida a los documentos prehispánicos que comienza en el siglo XVII, y del que uno de los episodios más ilustrativos es el largo debate en torno a la virgen de Guadalupe. Paralelamente a esta demanda, el conocimiento efectivo del territorio fue uno de los propósitos más definidos del reformismo dieciochista. Su puesta en práctica, largo tiempo reclamada por los criollos, no tardó en convertirse en un motivo para la protesta de los americanos, por el hecho de que los gobernantes destinados al efecto eran extraños a América. Como observa Virginia Gil Amate,

no dejará de aludirse a la necesidad de conocer para gobernar a lo largo del siglo XVIII, pero lo que en un primer momento se expresaba como punto lógico de la ciencia política, en los albores del siglo XIX, tomará la vehemencia de la abierta denuncia $^{42}$.

A pesar de todo esto, reconocer una expresa intencionalidad política en el sermón guadalupano de Mier obliga a olvidar varios aspectos. El primero es la dificultad para explicar tal sarpullido independentista en un fraile que sólo unas semanas antes había pronunciado un brillante sermón a la memoria de Hernán Cortés y que nunca había dado muestras de inquietudes políticas. Asimismo, identificar una intención política en el Sermón obligaría a desoír el cariz de las principales argumentaciones que, en el momento de su primera defensa, dio Mier para protegerse de sus cargos. La fundamental, a la que se subordinaban todas las demás, era su autoexculpación por haber sido víctima de las prisas, de la imprevisión y de una desafortunada consulta erudita. En definitiva, Mier reducía al absurdo el contenido de su sermón y, sobre todo, mostraba su sorpresa por el escándalo causado. Ésta era aún mayor al pensar que inicialmente había sido aplaudido y felicitado, incluso por las autoridades, y que, por lo tanto, el sermón no había podido causar el efecto para el que sus acusadores juzgaban que había sido preparado.

Ante todo, pues, el propio Mier llega a reducir al absurdo el problema causado por su sermón. Así cuando se refiere a las argumentaciones historio-

propagadas por muchos autores ilustrados europeos, entre ellos Buffon, quien propicia el comentario. Vid. Mier, «Quejas de los americanos», en Leopoldo Zea (comp.), Fuentes de la cultura latinoamericana, II, México, Fondo de Cultura Económica, 1993, págs. 379-390.

42 Virginia GIL Amate, «De españoles a americanos: variantes del criollismo en el siglo XVIII», Arrabal, 1 (1998), pág. 24. 
gráficas y teológicas que dominaron el debate de su encausamiento: «Hablaré claro: todo esto no es más que una comedia con dos actos y un entremés ${ }^{43}$. Su retractación ante el arzobispo usa la justificación de la falta de tiempo para no haber preparado una versión mejor documentada y retira así casi todo el crédito historiográfico de su versión guadalupana. El episodio de las Memorias que describe la elaboración de las hipótesis con que concurrió al púlpito comienza de hecho: «He aquí toda la trama: vamos a ver el nexo o nudo de la comedia» ${ }^{44}$. En esta fase, le sirvió de anticuario consejero el licenciado Borunda ${ }^{45}$. Para Cañizares-Esguerra, a pesar del carácter lunático de Borunda, su iniciativa historiográfica se alinea con las mismas intenciones del más fiable historiador Lorenzo Boturini (1702-c.1755): el asentamiento de una «epistemología patriótica» que se fundara sobre la custodia de las fuentes documentales, impidiendo su salida hacia los depósitos metropolitanos, además de asentarse en las potestades de los mexicanos, como americanos, para la interpretación de su pasado. Boturini se propuso, en 1742, reunir las fuentes de la historia prehispánica de Mesoamérica, una colección que los historiadores del siglo XVIII percibieron como la piedra angular del primer «archivo» de la identidad mexicana. Por este motivo, los franciscanos de Nueva España hurtaron la colección Boturini a la cuestación de los emisarios de la expedición Malaspina (1789) a su paso por el Virreinato, los cuales habrían embarcado los originales con destino a la Real Academia de la Historia en Madrid. Cañizares-Esguerra califica este hecho promovido por los franciscanos como una «conspiración criolla» ${ }^{46}$, y de hecho debe verse como una continuación expeditiva pero lógica de los trabajos científicos de Boturini.

La clarividencia que Mier pudo tener sobre este hecho en 1794, así como acerca de las implicaciones políticas de su sermón no parece demostrable, sino que forma parte de las especulaciones ajenas o de la reelaboración posterior de su significado por parte del fraile. Por las mismas razones, su insistencia

\footnotetext{
43 Mier, Memorias, pág. 120.

$44 \quad$ Ibid., pág. 66.

45 Las noticias sobre este abogado de la Audiencia novohispana son escasas, más allá de sus dudosas aportaciones al estudio de los jeroglíficos y antigüedades mesoamericanas, al que se dedicó como erudito curioso, y por el que llegó a recibir cierto prestigio en el Virreinato. Su Clave general de jeroglificos americanos (c. 1792), su obra más extensa y conocida, intentaba proporcionar una regla hermenéutica válida para toda la criptografía antigua mexicana desde una lectura alegórica de la Biblia. Sus resultados historiográficos, que componen un cuadro fantasioso y caótico, están condicionados por la finalidad de sus investigaciones: demostrar la igualdad de la historia americana en idéntico régimen que la universal y reservar su interpretación a los criollos. El notable estudio de Cañizares-Esguerra ni siquiera es capaz de aportar las fechas biográficas de Borunda, tal y como, sin embargo, aparecen en la mayoría de las figuras históricas a las que necesita referirse. Vid. su reseña vital en CAÑIZAREs-EsGuerra, loc. cit., págs. 305-312 y 318-320.

$46 \quad$ Ibid., pág. 301.
} 
en defender más tarde el contenido esencial del sermón sobre el que antes se había disculpado por su deficiente proceso de documentación, ha iluminado aspectos equívocos de la religiosidad del fraile. Debe tenerse en cuenta, no obstante, que se refieren a un momento muy posterior al del Sermón. Además de algunos indicios de su simpatía hacia el jansenismo y el protestantismo ${ }^{47}$, Mier llega a usar sus escritos biográficos para desprenderse de la sospecha de pertenecer a sociedades secretas, de modo muy marcado a la masonería, así como para exculpar a ésta de sus imputaciones históricas, sin que justifique a sus lectores la oportunidad y el énfasis de las disculpas ${ }^{48}$. A esto se une el notable anticlericalismo posterior de Mier, tachado de jansenista y próximo a ciertas ideas protestantes en sus ataques al alto clero novohispano ${ }^{49}$. La espiritualidad del padre Mier lo sitúa, así, en las corrientes del «catolicismo ilustrado» que nota Joël Saugnieux ${ }^{50}$ como espíritu del siglo, y dentro de una reforma espiritual ilustrada que casi en ningún caso cabría señalar como atea o propiamente jansenista, sino como nuevas formas de una espiritualidad razonada, ajena a los cultos exteriores.

47 Como Las Casas, Mier llega a impugnar la Conquista criticando el uso maquiavélico de imágenes sagradas contra los indios. Lo que más asombra es que el fraile, que en París formó parte del clero que juró la constitución republicana, critique el uso mismo de las imágenes, por el riesgo de idolatría en sustituir las imágenes prehispánicas por las católicas a indios que no sabían de su significado: «Yo lo que creo es a Dios, el cual dice "yo soy Dios y no me mudo": ego Deus et non mutor. Y este Dios tan celoso de que no se reparta o equivoque el culto que le es debido, que por primer precepto del Decálogo mandó que no se hiciera imagen ni semejanza alguna (Exodi, 20, v. 4) [...] y que en el Deuteronomio (Cap. 4, vv. 15 y 16) dice a su pueblo que no se dejó ver en Oreb para que no hiciesen alguna imagen de él en figura de hombre o de mujer [...], hubiera sido el autor de la idolatría, pues esta no consiste precisamente en el objeto [...], sino en la intención y manera, y esta no la sabían los indios». Mier, Memorias, págs. 125-126. Más adelante, esgrime las críticas protestantes a las imposturas católicas: “¿Qué dirían los ministros protestantes a sus ovejas si cayese en sus manos el edicto del Sr. Haro? "Ved aquí cómo los obispos católicos engañan a su pueblo. Ved cómo el culto católico-romano no se sostiene sino a fuerza de imposturas"». Ibid., pág. 142. En la pág. 79 comienza dudando de la historicidad de las apariciones marianas, ya que su inexistencia no violaría la letra de «la ley de Sión».

48 Ibid., págs. 335-338.

49 Villoro ha estudiado este aspecto del pensamiento de Mier, recogiendo las ocasiones en las que el fraile aleja de sí la sospecha de jansenismo o apostasía, y explica su postura contra Roma como una defensa verdadera del catolicismo. Villoro, loc. cit., págs. 129-133. Pese a renunciar a los votos de su Orden y a sus proclamas contra el uso de la religión como argumento para el despotismo español, Mier nunca discutió, sin embargo, su obediencia a Roma como católico, ni dejó de litigar por su autoridad y derechos canónicos como doctor en teología, tal como subraya Edmundo O'Gorman para defender su profunda fe católica, a pesar de sus acercamientos a formas del deísmo, el protestantismo y aun de la masonería. Vid. O’Gorman, «Prólogo» a MIER, Ideario político, págs. X-XI. En cuanto a su filiación con la masonería, los editores de la Historia de Mier dan por cierta su relación con las logias londinenses, pese a que, consideran, Mier «se cuida de hablar de ello en sus Memorias». Vid. SainT-Lu y Bénassy-Berling, loc. cit., págs. XVII-XVIII.

50 Vid. Joël SAugnieux, Le jansenisme espagnol du XVIIIe siècle: ses composantes et ses sources (prólogo de José Miguel Caso González), Oviedo, Cátedra Feijoo / Facultad de Filosofía y Letras de la Universidad de Oviedo, 1975. 
Lo más prudente es aplazar la actividad de Mier como propagandista del independentismo hasta su estancia en Londres. Para los editores de la Historia de Mier, este periodo constituye «un giro fundamental» en la vida, la obra y la formación ideológica de Mier, pues «es en Londres [...] donde este aventurero, hasta entonces desconocido y un poco extravagante, alcanza su dimensión de personaje político de primer plano $»^{51}$. El sentimiento independentista o antiespañol no es verificable en el ideario de Mier hasta su exilio en Londres. Sólo entonces puede comenzar a observarse una actitud lascasiana que trata de negar a España la legitimidad de sus títulos de posesión. La actividad propagandística de Mier comienza, pues, con su labor editora de la obra de Bartolomé de Las Casas. Además, la Apología, escrita en su prisión de 1817, responde de hecho a un ideal lascasiano, y se inspira en la forma con que fray Bartolomé de Las Casas organizó su Brevísima relación de la destrucción de las Indias (1552), en segmentos narrativos divididos según los lugares geográficos de la historia. La presencia del testimonio lascasiano se remonta, sin embargo, a su etapa londinense. Mier llegó a editar y prologar la mencionada obra del también dominico como parte de su propaganda independentista. Las distintas ediciones realizadas por fray Servando de la Brevísima, en Londres (1812), Filadelfia (1821) y México (1822), fueron las primeras publicaciones del panfleto en español después de la edición original de Sevilla y la de Barcelona en 1646. Asimismo, Mier continuó por su cuenta la defensa histórica del obispo de Chiapas, ocupándose de rebatir la versión que sostenía que la propuesta de Las Casas, en 1516, de introducir esclavos negros en el Nuevo Mundo para proteger del trabajo forzado a los nativos había implantado la esclavitud en el Continente ${ }^{52}$.

51 Saint-Lu y Bénassy-Berling, loc. cit., pág. XVIII.

52 Mier fue de hecho el primer autor en denunciar este error historiográfico, en el Libro XIV de su Historia de la revolución de la Nueva España, así como en identificar la fuente de la calumnia, que se encuentra en el historiador escocés William Robertson, católico prohispánico que contestaba de esta forma a la «leyenda negra» contra España. En su History of America (1777), Robertson pretendió establecer que la propuesta de Las Casas para la sustitución del trabajo forzoso de los nativos americanos por esclavos impuso esta institución en la economía indiana, ignorando, sin embargo, que esta era una práctica habitual desde los tiempos de los Reyes Católicos, y aparece reglada ya entonces en las reglamentaciones reales. Por otra parte, debe destacarse que la propuesta de Las Casas no se limitaba a los negros africanos, al menos en el primer texto, la Relación de los remedios que parecen necesarios para que el mal y el daño que han las Indias cese (1516), sino que se refería a «esclavos negros y blancos que los puedan llevar de Castilla». No así en el Memorial de remedios para las Indias (1518). Para este asunto, vid. José Antonio SAco, Historia de la esclavitud (A. Garzón del Camino, ed.), Buenos Aires, Editorial Andina, 1965 [1. a ed., La Habana, 1879], págs. 163-169; Fernando OrTiz, Contrapunteo cubano del tabaco y el azúcar (Enrico Mario Santí, ed.), Madrid, Cátedra, 2002 [1. a ed., La Habana, 1942], págs. 552-627; Cañizares-Esguerra, loc. cit., págs. 53-55, y José AlCina Franch, «Introducción» a Bartolomé de las Casas, Obra indigenista (José Alcina Franch, ed.), Madrid, Alianza, 1995, pág. 18. En la Historia de 
No obstante, donde mejor se aprecia la nueva función de Mier como propagandista de la causa de la independencia de la América española es en las dos cartas dirigidas a El Español para protestar contra las tesis de su redactor, José María Blanco White. En su número XIX, del 30 de octubre de 1811, el periódico publicaba una nota criticando la decisión de la Junta de Caracas, que había declarado la Independencia de Venezuela el 5 de julio de ese año ${ }^{53}$. Mier publica una Carta de un Americano al Español sobre su número XIX, firmada como V.C.R. y editada en la imprenta de W. Lewis el 26 de diciembre del mismo año, con el fin de justificar la independencia y preconizar la guerra. Blanco White le responde con un artículo que abre el número XXIV de $E l$ Español, del 30 de abril de 1812, titulado «Contestación a un papel impreso en Londres con el título de Carta de un Americano al Español, sobre su número $X I X{ }^{54}$. La contestación de Blanco White se siguió de la contrarréplica de Mier, con una Segunda carta de un Americano el Español sobre su número XIX. Contestación a una respuesta dada en el número XXIV, publicada en la imprenta de Guillermo Glindon a finales de julio de 1812, donde Mier abundaba en las razones anteriores. Blanco White responde en su «Contestación a la Segunda Carta de un Americano al Español ${ }^{55}$, en la que pasa a denunciar las responsabilidades del gobierno de Cádiz en el fracaso de una mediación reconciliadora, y recapitula, como había hecho hasta entonces, las reivindicaciones legítimas de los americanos. Este texto habría de verse prolongado por una última "Carta al Americano sobre la rendición de Caracas» ${ }^{56}$. En ella, Blanco analiza con lucidez las causas de la reciente caída de la Primera República: la superstición desatada por el clero entre el pueblo a causa del terremoto de ese año y la fácil reconquista de Caracas a cargo de Morillo, aprovechando la

las Indias, Las Casas se refiere a su propuesta, de la que más tarde se arrepentiría. En los capítulos 102 y 129 del tercer volumen de la misma, evidencia su retractación: «Este aviso de que diese licencia para traer esclavos negros a estas tierras dio primero el clérigo Casas, no advirtiendo la injusticia con que los portugueses los toman y hacen esclavos; el cual, después de que cayó en ello, no lo diera por cuanto había en el mundo, porque siempre los tuvo por injusta y tiránicamente hechos esclavos, porque la misma razón es dellos que de los indios» (Bartolomé de las Casas, Historia de las Indias. Tomo III (André Saint-Lu, ed.), Caracas, Biblioteca Ayacucho, 1986, pág. 371); «Deste aviso que dio el clérigo, no poco, después, se halló arrepiso, juzgándose culpado por inadvertente [...]» (ibid., pág. 474).

53 Vid. [José María Blanco White], «Independencia de Venezuela», El Español, número XIX (30 de octubre de 1811), tomo IV, págs. 42-50.

54 Vid. [Blanco White], «Contextación a un papel impreso en Londres con el título de Carta de un Americano al Español, sobre su número XIX», El Español, número XXIX (30 de abril de 1812, aunque la portada introduce por error el año 1810), tomo IV, págs. 409-425.

55 Vid. [Blanco White], «Contestación a la Segunda Carta de un Americano al Español», El Español, número XXVIII (30 de agosto de 1812), págs. 274-285.

56 Vid. [Blanco White], «Carta al Americano sobre la rendición de Caracas», El Español, número XXX (30 de octubre de 1812), págs. 410-425. 
desorganización y la división de los patriotas, fueron analizadas a la luz de las mismas acusaciones que había vertido Blanco sobre la precipitación de la Independencia.

Tal como notan los editores de la Historia de Mier, la polémica con Blanco White es, en buena medida, una falsa polémica ${ }^{57}$. Por lo pronto, ambos compartían el interés en la independencia americana. Blanco no ocultaba su simpatía por esta causa en el artículo que suscitó la polémica con Mier. La precaución que invoca Blanco es, por eso, un medio de preservar las posibilidades de su éxito. Refiriéndose a la proclamación de la Independencia en Caracas, el sevillano aseguraba entonces: «Tanto entusiasmo como me causó la moderación de la primer Junta de Caracas, tanto desaliento me ha inspirado esta imprudencia $»^{58}$. Sin dejar de reconocer el derecho de los venezolanos a su independencia, lo que más parece lamentar Blanco es la justificación que se le ofrece a la causa absolutista y las dificultades en que se pone a los amigos peninsulares de la Independencia: «Si declarar la absoluta independencia fuera lo mismo que asegurarla, lo que más se podría decir de Venezuela es que usaba de su derecho sin contemplaciones», pero, prosigue el redactor de El Español:

si declarando la absoluta independencia no hace más que aumentar las dificultades de cimentar la felicidad de aquellos países, multiplicar el número de sus contrarios, convertir en tales a los indiferentes, y poner a una prueba peligrosa a sus amigos ¡quién podrá tener a esta determinación por efecto de un maduro examen, y no por un desquite imprudente, cuando menos ${ }^{59}$ !

La coincidencia profunda entre Mier y Blanco ha sido resaltada indirectamente por André Pons, al señalar la influencia de Blanco White en Bolívar, y las deudas de éste con el pensamiento político de Mier, por encima de las divergencias que antes parecieran existir entre Blanco y el dominico ${ }^{60}$. De este modo, Mier y Blanco White no sólo coincidirían desde el principio en la legitimidad de la Independencia, sino que, hasta ese momento, estarían de acuerdo en la eventual adopción de un modelo democrático prudente, semejante al inglés. Tal vez, por lo mismo, no se pueda estar de acuerdo con una parte de la argumentación de Pons, cuando pretende oponer tajantemente a Mier y a Blanco, con el fin de destacar las relaciones entre el pensamiento del último y el de Bolívar. La

57 Vid. Saint-Lu y Bénassy-Berling, pág. XXXI.

58 [Blanco White], «Independencia de Venezuela», pág. 42.

59 Ibid., pág. 43.

60 Vid. André Pons, «Bolívar y Blanco White», Anuario de Estudios Americanos, LV, 2 (1998), págs. 507-529. 
oposición que defiende Pons sólo se sostiene en lo que atañe a la discusión sobre el momento oportuno para la independencia. Sólo esto permitiría discriminar a Mier y Miranda de la mayor prudencia de Blanco y Bolívar ${ }^{61}$. Nunca, sin embargo, terminarán de oponerse la prudencia de éstos a la cautela constitucionalista del fraile y del precursor caraqueño, como se verá más adelante. En este sentido, contra «la anarquía y el sistema revolucionario», Miranda no veía alternativa: «Sería mejor si las colonias se quedaran otro siglo más bajo la opresión bárbara y vergonzosa de España ${ }^{62}{ }$.

Por su parte, la Historia de la revolución de Nueva España, con la que Mier cumple en 1813 el encargo recibido dos años antes, debe suponer la consideración de fray Servando como una figuras influyentes en el pensamiento de la emancipación. A pesar de algunas exageraciones en la interpretación histórica y de la caótica composición del libro, las opiniones de Mier en su Historia terminan mostrando una integridad que le reporta la sincera admiración de Bolívar ${ }^{63}$. A pesar de la oposición de Bolívar a la postura representada por Mier en su polémica con Blanco White, el propio Pons no deja de señalar algunas deudas del Libertador con el pensamiento del fraile, sobre todo con propuestas que no se relacionan tanto con la lucha emancipadora, como con la eventual administración de la victoria. La deuda más importante es hacia la idea de unidad y fortaleza nacional que esgrime Mier en su Segunda carta $^{64}$. Más aún, el gesto mismo de esta composición, que significaba la primera historia de la independencia de la América Española, supuso el reconocimiento de la historiografía independentista posterior hacia el que podía considerarse como uno de los primeros ideólogos pragmáticos de la causa emancipadora. Brading recoge las deudas manifiestas de los historiadores independentistas con Mier, citando a Andrés Quintana Roo,

\footnotetext{
${ }_{61} \quad$ Ibid., pág. 519.

62 Citado en. Manfred Коssoк, «La sal de la revolución. El jacobinismo en Latinoamérica. Intento de una determinación de posiciones», Historia y sociedad, 13 (1977), pág. 25.

63 Por ejemplo, en la «Contestación de un americano meridional...», Bolívar cita a Mier por el seudónimo de «José Guerra» con que había firmado su Historia de la revolución de Nueva España. El caraqueño sostiene lo desprevenido e improvisado de la independencia hispanoamericana, usando las tesis de Mier sobre el carácter de los primeros acuerdos entre la Corona española y los descubridores y conquistadores, los cuales habrían implantado un feudalismo secular que le hace afirmar que «será fácil colegir que la América no estaba preparada para desprenderse de la metrópoli». Esto le hace solicitar la prudencia y la paciencia necesarias para unos pueblos marginados de su propio gobierno e inexpertos en la ciencia política. Bolívar no cita su fuente, pero extrae la referencia del libro XIV, último, de la Historia de Mier. No se puede suponer que Bolívar ignorara la identidad real del autor de la Historia, lo que ayuda a cuestionar una oposición definitiva entre el pensamiento histórico de Mier y el del Libertador. Vid. BoLívar, «Contestación de un americano meridional...», loc. cit., pág. 64.

64 Vid. Pons, loc. cit., pág. 522. Pons compara la idea que expresa Bolívar en su Carta de Jamaica (1815) de formar un congreso panamericano junto al istmo de Panamá con esta misma propuesta en la Segunda carta de Mier.
} 
Carlos María Bustamante o Lucas Alamán ${ }^{65}$. Lo temprano de su publicación respecto al proceso emancipador favoreció que la influencia de la Historia fuera, asimismo, política ${ }^{66}$.

\section{Idea constitucionalista en la «Profecía»}

El último nudo discursivo entre los escritos políticos del padre Mier es el conocido como Discurso de las profecías, donde advierte al Congreso Constituyente mexicano de 1823 de los peligros de un federalismo para el que juzga que los mexicanos no estaban preparados. El discurso se dirige al restaurado Congreso, después de que Iturbide fuera depuesto por la rebelión de Santa Anna. Afirma entonces Mier: «Yo siempre he estado por la federación, pero una federación razonable y moderada, una federación conveniente a nuestra poca ilustración y a las circunstancias de una guerra inminente, que debe hallarnos unidos» ${ }^{67}$. El discurso muestra a un Mier, que, como Bolívar, había dado un margen de confianza a un ideario democrático que con el tiempo comienza a trocar en un declarado posibilismo político. Lo curioso del repliegue conservador de Mier es que éste se produce después de su conversión al republicanismo neto del modelo de los Estados Unidos, durante su exilio en Filadelfia, entre 1820 y 1822. Mier abandonaba el democratismo liberal inglés monárquico y parlamentario y abrazaba el modelo norteamericano, republicano y federal. No obstante, debe tenerse en cuenta que este cambio de opinión no altera la moderación que seguirá dirigiendo las preferencias de Mier, sino que es obligado por la necesidad de prescindir de la solución monárquica. En esta evolución, impera el contexto mexicano, en el que Iturbide ofrece una solución autonomista bajo la égida borbónica, según establecían el Plan de Iguala y los Tratados de Córdoba (1821). Para Mier, Iturbide trataba de enmascarar la ya inevitable secesión mexicana con la adhesión monárquica de la nación a Fernando VII. La necesidad de rechazar esa solución engañosa dicta el nuevo republicanismo de Mier, quien, sin embargo, no deja de advertir de los riesgos de copiar servilmente el utopismo republicano del norte. Contra los peligros de la anarquía y la tiranía, su crítica al federalismo se dirige a

65 Vid. Brading, «Prefacio» a Mier, Historia, pág. V; Saint-Lu y Bénassy-Berling, «Influencia de la Historia en la historiografía de la Independencia», loc. cit., págs. CI-CX.

66 Vid. Saint-Lu y Bénassy-Berling, «Influencia de la Historia en la ideología de la Independencia: Mier y Bolívar», loc. cit., págs. XCIX-C.

${ }_{67}$ Mier, «Profecía del doctor Mier sobre la federación mexicana», en Ideario político, pág. 294. Mier se refiere al temor de una guerra de reconquista por parte de la Santa Alianza. 
los constituyentes que trataban de remedar el modelo de la Carta Constitucional de los Estados Unidos y el de la Constitución liberal de Cádiz.

Por eso, Mier sigue reclamando moderación en las reformas, al igual que habían hecho Blanco White o Bolívar. Los debates en el seno de la nueva nación mexicana rescatan la dialéctica entre girondinos y jacobinos, con la curiosa salvedad de que, como nota Justo Sierra,

los jacobinos [...] en lugar de ser centralistas como en Francia, fueron federalistas y proyectaban una república calcada sobre la norteamericana, cuya Constitución [comenta Sierra con ironía] habían someramente estudiado ${ }^{68}$.

Tanto Mier como Bolívar deben enfrentarse a los primeros intentos constitucionalistas de unas repúblicas erigidas con frecuencia sobre la retórica de la Ilustración, a las cuales ellos mismos habían ayudado a nacer, y que, sin embargo, ven en el riesgo de dejarse arrastrar por el optimismo ingenuo. El Bolívar que avisaba al Congreso de Angostura (1819) de que «cuanto más admiro la excelencia de la Constitución Federal de Venezuela, tanto más me persuado de la imposibilidad de su aplicación a nuestro estado ${ }^{69}$, federalismo en el que no dejaba de predecir «la muerte del gobierno, cuyos herederos son la anarquía, la usurpación y la tiranía ${ }^{70}$, podría ser el mismo Mier que comenzaba defendiéndose «¿se podrá dudar de mi republicanismo?», para aclarar que «yo también fui jacobino» ${ }^{71}$, recordando la polémica con Blanco White y reafirmando su compromiso la independencia como única solución digna, para concluir, sin embargo, que «querer desde el primer ensayo de la libertad remontar hasta la cima de la perfección social, es la locura de un niño que intentase hacerse un hombre perfecto en un día ${ }^{72}$. Asimismo, «el pueblo siempre ha sido víctima de la seducción de los demagogos turbulentos, y su voluntad numérica es un fanal muy oscuro» ${ }^{73}$. Por eso, busca esa «nación sensata [que] no gusta de principios generales ni máximas abstractas, porque son impertinentes para el gobierno del pueblo» ${ }^{74}$.

En el contexto ideológico de la independencia mexicana, Luis Villoro, ha calificado de «instantaneísmo popular» ${ }^{75}$ la demagogia democrática que pre-

\footnotetext{
${ }^{68}$ Justo SiERra, Evolución política del pueblo mexicano (prólogo y cronología de Abelardo Villegas), Caracas, Biblioteca Ayacucho, 1977 [1. a ed., México, 1940], págs. 130-131.

69 Bolívar, «Discurso de Angostura», loc. cit., pág. 108.

$70 \quad$ Ibid., pág. 118.

71 Mier, Profecía, págs. 289 y 293.

72 Ibid., pág. 290.

73 Ibid., pág. 292.

$74 \quad$ Ibid., pág. 297.

75 Vid. Villoro, loc. cit., págs. 71-105.
} 
tendía la abolición de las estructuras de poder. Al analizar los discursos de Mier al Congreso Constituyente, Villoro considera que el interés de la obra del fraile debe remontarse a una crítica general a este utopismo, y que la Profecía puede considerarse, de hecho, como el primer planteamiento mexicano del tema enseguida fecundo de la «revolución desdichada» ${ }^{76}$. Su crítica al utopismo debe entenderse dentro de la misma intención con que otros autores de la época restaban su prestigio causal a las Luces europeas en la Independencia y defendían una relativa pervivencia del pasado virreinal. Así, el fraile explica en sus Memorias que los logros del liberalismo poseían un probado origen cristiano, ya que:

la doctrina del librito o la declaración de los derechos del hombre, ya proclamada por los Estados Unidos de América, y después por la Asamblea Nacional de Francia, son, en sustancia, principios eternos muy bien reconocidos por los [autores] españoles antes de la invasión del despotismo, que aborrece la luz, porque obra mal ${ }^{77}$.

Villoro señala toda una tradición de crítica al utopismo racionalista que acompañó o, más a menudo, se limitó a secundar el pensamiento político del padre Mier. El tema de la revolución desdichada que habría abierto el fraile encuentra en el federalismo la razón emblemática que hallaron numerosos autores para criticar un utopismo que terminó conduciendo la nación mexicana a la ruina. Villoro recoge, entre otros, los testimonios históricos de José María Luis Mora (1794-1850), Lorenzo de Zavala (1788-1837) y Lucas Alamán (1792-1853). El primero compuso un Discurso sobre el curso natural de las revoluciones (1836), en el que habla de dos tipos de revoluciones: las felices y las desdichadas. Después de afirmar, como podría hacerlo Mier, que, aun cuando todas las revoluciones «dependen de un movimiento general en el espíritu de las naciones», puesto que «todos quieren mudar de situación, mas ninguno sabe a punto fijo lo que desea $»^{78}$, y que, en resumen, a todos los hombres les posee «la desesperación por no llegar a ser uno mismo» ${ }^{79}$, Mora observa, sin embargo, que las revoluciones desdichadas, como la mexicana, se caracterizan por no detenerse en sus objetivos exteriores, sino por abandonarse a la pulsión de ese espíritu histórico y a la impotencia de la libertad abstracta. De aquí habrían derivado las soluciones ideológicas que «se separan del mundo real para ocuparse del ideal» y que «tratan de dar leyes a un pueblo que no existe en la imaginación de los políticos, sino

$76 \quad$ Ibid., pág. 234.

77 Mier, Memorias, págs. 242-243. Las cursivas son del texto.

78 Citado en Villoro, loc. cit., pág. 232. Las cursivas son del texto.

$79 \quad$ Ibid., pág. 233. 
en la superficie de la tierra ${ }^{80}$. A su vez, el testimonio de Alamán en su Historia de Méjico aboga por una solución "preterista», como la denomina Villoro, en el rumbo político de la nueva república. Según Alamán, el error de la revolución emancipadora habría estado en su ruptura de la continuidad histórica. Los criollos borraron el pasado de la Conquista «con una especie de frenesí imposible de explicar, como si fuesen los herederos de los pueblos conquistados y estuviesen en la obligación de vengar sus agravios $»^{81}$. Alamán explica que el criollo no es el antihispanista que elige ser, sino el descendiente de españoles que es, y que su ascendencia le señala «deberes». Si, como plausiblemente defiende Villoro, los testimonios de estos autores contra el utopismo derivan directamente del legado del padre Mier, especialmente de su labor constitucionalista, su retrato picaresco y novelesco debe ser sustituido por otro que, como hicieron muchos de los autores contemporáneos del fraile regiomontano y han hecho una buena parte de los historiadores más recientes, permita destacar la complejidad ideológica del personaje.

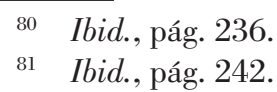

